\title{
Occurrence of different strains of Babesia canis in dogs in eastern Poland
}

\author{
Paweł Łyp, Michał Bartnicki, Marta Staniec, \\ Stanisław Winiarczyk, Łukasz Adaszek \\ Department of Epizootiology and Infectious Diseases, Faculty of Veterinary Medicine, \\ University of Life Sciences Lublin, 20-612, Lublin, Poland \\ pawel.1yp86@gmail.com
}

Received: May 10, $2016 \quad$ Accepted: November 16, 2016

\begin{abstract}
Introduction: The aim of this study was to carry out a genetic analysis of Babesia canis isolates detected in dogs in eastern Poland and to study the correlation of the protozoa variant with a specific geographical region. Material and Methods: PCR was used to identify strains of $B$. canis from naturally infected animals ( $240 \mathrm{dogs}$ from four provinces: Mazowieckie, Lublin, Podlasie, and Podkarpacie) by amplifying and sequencing a fragment of the 18S rRNA gene. Results: Sequencing the PCR products led to the identification of four variants of B. canis. Two previously described protozoa variants (18S rRNA-A and 18S rRNA-B) were observed in all provinces. Additionally, in the Mazowieckie and Lublin provinces a B. canis variant which contributed to the development of acute or atypical babesiosis was observed. The fourth variant of $B$. canis was detected only in dogs from the Lublin province, and the course of the disease was subclinical in all dogs infected with this variant. Conclusion: These results indicate the appearance of a new fourth $B$. canis genotype in Poland and confirm that it is still necessary to study the relationships between the genetic structure of protozoa, geographical distribution of the parasites, and clinical course of the disease.
\end{abstract}

Keywords: dog, Babesia canis, 18S rRNA, PCR, Poland.

\section{Introduction}

Canine babesiosis is a disease caused by parasites of the genus Babesia (1). Numerous species of Babesia exist worldwide. Parasite blood smears have recognised them as forming two groups: the large form $(3-5 \mu \mathrm{m})-$ B. canis, and the small form $(1-3 \mu \mathrm{m})-B$. gibsoni. Based on its geographic distribution, hosts, modes of transmission, pathogenicity, and the results of molecular studies, B. canis has been reclassified into four species: B. canis, B. rossi, B. vogeli, and the unnamed Babesia sp. detected in North America (7, 15, 18). All of these pathogens cause fever, pigmenturia, and haemolytic anaemia. In particular cases the outcome of the disease may be fatal $(4,13)$. Moreover, significant deviations from the standard results of serum biochemical tests may be observed in infected dogs (20).

Blood smear examination is a useful diagnostic tool for detection of clinical babesiosis in dogs.
Microscopic evaluation continues to be the easiest and most accessible diagnostic test for most veterinary practitioners. However, the sensitivity of this method is lower than that of molecular diagnosis. Although light microscopy is highly specific and can be used to diagnose the majority of dogs infected by the large forms of Babesia (e.g. B. canis), it is less effective at detecting $B$. gibsoni infections. The small piroplasms are hard to observe using light microscopy, which has relatively poor to moderate sensitivity, and expertise is required (16).

PCR and the sequencing of amplification products are being used with increasing frequency in the diagnosis of babesiosis and the assessment of the epizootic situation, including the detection of subclinical infections with $B$. canis protozoa (14). The genetic analysis of Polish isolates of $B$. canis allowed three groups of parasites to be identified: $18 \mathrm{~S}$ rRNA-A, 18S rRNA-B (1), and the new and yet-unnamed 18S rRNA strain responsible for subclinical babesiosis (13). 
The aim of this study was to perform a genetic analysis of $B$. canis isolates detected in dogs in eastern Poland and to possibly identify whether the occurrence of each protozoa strain could be correlated with a specific geographical region.

\section{Material and Methods}

Animals. The study was conducted in four eastern Polish provinces (Lublin, Mazowieckie, Podlasie, and Podkarpacie) from March 2015 to March 2016. It included 240 dogs (60 animals from each province, 182 males and 58 females, with ages ranging from 6 months to 11 years) with babesiosis confirmed by blood smear analysis and/or the results of PCR. In 198 animals, clinical examination revealed symptoms of acute babesiosis (fever, weakness, pallor of mucous membranes, and jaundice). Other dogs diagnosed showed atypical signs of the disease (anaemia and weakness), or their clinical examination did not reveal any abnormalities (subclinical infection). The dogs with subclinical infection were classified based on the presence of the ticks on their bodies and the results of haematological examination. All animals had thrombocytopenia $\left(\mathrm{PLT}=12-88 \times 10^{9} / \mathrm{L}\right)$ and mild anaemia $\left(4.5-5.3 \times 10^{12} / \mathrm{L}\right)$.

Characteristics of provinces. Lublin province is situated mainly between the Vistula and Bug Rivers, and is divided into three geographically diverse areas: the hilly Lublin Upland with ravines; the forested Lublin Lowlands, and Leczna/Wlodawa with its large lakes. Mazowieckie is a low-lying region 57$325 \mathrm{~m}$ above sea level and is divided by the three main rivers: the Vistula, Bug, and Narew. Podlasie is an area lower than $299 \mathrm{~m}$ above sea level, topographically marked by postglacial lakes, marshland, and peat bogs. Podkarpacie in the south-eastern corner of Poland has a diverse natural environment.

The climate of these provinces is mostly continental, with average temperatures of 7 to $8^{\circ} \mathrm{C}$, average annual precipitation from 500 to $1200 \mathrm{~mm}$, and a growing season ranging from 180 to 220 days. The mainly coniferous forests cover $21.7 \%-39.5 \%$ of the regions, arable soil by area is $37.2 \%-55.9 \%$, and meadows spread over $7.7 \%-20.0 \%$.

Collection of blood samples and their analysis. The study was performed at the Clinic of Infectious Diseases, Faculty of Veterinary Medicine, University of Life Sciences in Lublin. Whole blood (EDTA) was taken from all animals for microscopic examination as well as molecular (PCR) tests. One drop of blood from each sample was used to prepare blood smears stained by the May-Grünwald-Giemsa method. The remaining blood was frozen at $-20^{\circ} \mathrm{C}$ for further analysis - DNA extraction for PCR using a DNA Blood kit (A\&A biotechnology, Poland).

Molecular analysis. Amplification of the fragment of the $18 \mathrm{~S}$ rRNA of $B$. canis gene with a size of 559 bp was performed using the pair of primers: BAB GF2 (5'-GTC TTG TAA TTG GAA TGA TGG$\left.3^{\prime}\right)$ and BAB GR2 (5'-CCA AAG ACT TTG ATT TCT CTC-3') (1).

PCR was carried out in $50 \mu \mathrm{L}$ of total reaction volume containing: $100 \mu \mathrm{M}$ of each dNTP, $1.6 \mathrm{mM}$ of $\mathrm{MgCl}_{2}, 0.25 \mu \mathrm{M}$ of each primer, $2.5 \mathrm{U}$ of Taq DNA polymerase, and $5 \mu \mathrm{L}$ of DNA template. Amplification of parasite DNA was performed in a Biometra thermocycler (Germany). Cycling conditions for B. canis were: initial denaturation at $92^{\circ} \mathrm{C}$ for $2 \mathrm{~min}$, followed by 50 cycles of denaturation at $92^{\circ} \mathrm{C}$ for $60 \mathrm{~s}$, annealing at $52^{\circ} \mathrm{C}$ for $60 \mathrm{~s}$, extension at $72^{\circ} \mathrm{C}$ for $90 \mathrm{~s}$, and a final extension at $72^{\circ} \mathrm{C}$ for $5 \mathrm{~min}$. Positive and negative controls were included in all amplifications. The PCR products were separated by electrophoresis on $1 \%$ agarose gel and visualised using ethidium bromide $(1 \mu \mathrm{g} / \mathrm{mL})$.

The amplicons were purified on QIAquick spin columns (Qiagen, USA) and eluted in $50 \mu \mathrm{L}$ of $10 \mathrm{mM}$ Tris, $\mathrm{pH}$ 7.6. The DNA sequence was determined on both strands using the same primers as for PCR at a DNA sequencing core facility (Research Institute, Polish Academy of Sciences). The DNA sequences were assembled and edited using SeqMan (DNAstar, Lasergene, USA), and ClustalV alignments.

\section{Results}

Confirmation of babesiosis. Analysis of blood smears confirmed babesiosis in 198 animals (82.5\%). In each case merozoites or trophozoites of Babesia were observed within red blood cells. The positive results of the microscopy test were confirmed by positive results of PCR in each case. All dogs demonstrated symptoms of acute babesiosis, including: fever, weakness, pallor of mucous membranes, jaundice, or haemoglobinuria.

Microscopic blood examination in the remaining 42 dogs did not demonstrate the presence of protozoa in the erythrocytes. The infection in the animals was confirmed only by PCR results. The course of babesiosis in 31 animals was non-typical, with the dominating symptoms of anaemia and severe weakness recurring every few days. The pet owners reported that the symptoms prevailed for about five to seven weeks. In the remaining 11 dogs no symptoms of babesiosis were observed. All dogs in this group had a history of contact with ticks.

Results of molecular analysis in connection with the clinical course of the disease. A fragment of B. canis DNA with a size of 559 bp was detected in all animals. The analysis of the $18 \mathrm{~S}$ RNA gene fragment sequence helped to identify four polymorphic groups of protozoa. Isolates of $B$. canis with a common sequence were classified into the first group to a total of 107 , demonstrating 100\% homology with the previously described B. canis 18S rRNA sequence EU622792 available in the NCBI GenBank (Fig. 1). 
Fig. 1. Nucleotide sequence of $18 \mathrm{~S}$ rRNA gene fragment from own isolates classified in the first group. Position of mutations in polymorphic groups 2,3 , and 4 are marked

\begin{abstract}
3'-GTCTTGTAATTGGAATGATGGTGACCCAAACCCTCACCAGAGTAGCAATTGGAGGGCAAGTCTGGTGCCAGCAGCC GCGGTAATTCCAGCTCCAATAGCGTATATTAAACTTGTTGCAGTTAAAAAGCTCGTAGTTGTATTTTTGCGTTAGCGGTT TGACCATTTGGTTGGTTATTTCGTTTTCGCTTTTGGGAATTTCCCTTTTTACTTTGAGAAAATTAGAGTGTTTCAAGCAGA CTTTTGTCTTGAATACTTCAGCATGGAATAATAGAGTAGGACTTTGGTTCTATTTTGTTGGTTATTGAACCTTAGTAATG GTTAATAGGAACGGTTGGGGGCATTCGTATTTAACTGTCAGAGGTGAAATTCTTAGATTTGTTAAAGACGAACTACTGC GAAAGCATTTGCCAAGGACGTTTCCATTAATCAAGAACGAAAGTTAGGGGATCGAAGACGATCAGATACCGTCGTAGT CCTAACCATAAACTATGCCGACTAGTGATTGGAGGTCGTCGTTTTTTGACCCCTTCAGGAACTTGAGAGAAATCAAAGT CTTTGG-5'
\end{abstract}

Isolates of protozoa demonstrating $100 \%$ similarity with the $B$. canis $18 \mathrm{~S}$ RNA sequence EU622793 available in NCBI GenBank were classified into the second group in 84 cases. In the investigated 18S rRNA gene sequences all isolates of the EU622792 group have guanine in position 150 and adenine in position 151, whereas the isolates of the EU622793 group have adenine in position 150 and guanine in position 151. A microscopic examination revealed the presence of the protozoa in the blood of all dogs infected with the two strains mentioned, and the animals demonstrated symptoms of acute infection.

Group three covered 38 isolates characterised by $100 \%$ mutual homology. All Babesia isolates obtained from this group had thymine in positions 150 and 151 . A microscopic test of blood samples from 31 dogs in this group did not reveal the presence of protozoa in the erythrocytes, and the course of the disease was nontypical. Dogs infected with the other seven strains of this group demonstrated symptoms of acute babesiosis and the haematological examination revealed the presence of merozoites in the erythrocytes.

Table 1. The differences in the nucleotide substitutions in the $B$. canis $18 \mathrm{~S}$ rRNA gene fragment in four polymorphic groups detected in the study

\begin{tabular}{|c|c|c|c|}
\hline $\begin{array}{l}\text { Polymorphic } \\
\text { group }\end{array}$ & $\begin{array}{l}\text { Number. of } \\
\text { isolates }\end{array}$ & Mutation & Position \\
\hline No. 1 & 107 & - & - \\
\hline No. 2 & 84 & $\mathrm{GA} \rightarrow \mathrm{AG}$ & 150,151 \\
\hline No. 3 & 38 & $\mathrm{GA} \rightarrow \mathrm{TT}$ & 150,151 \\
\hline \multirow{11}{*}{ No. 4} & \multirow{11}{*}{11} & $\mathrm{~A} \rightarrow \mathrm{C}$ & 221 \\
\hline & & $\mathrm{G} \rightarrow \mathrm{C}$ & 222 \\
\hline & & $\mathrm{A} \rightarrow \mathrm{C}$ & 223 \\
\hline & & $\mathrm{G} \rightarrow \mathrm{C}$ & 224 \\
\hline & & $\mathrm{T} \rightarrow \mathrm{C}$ & 225 \\
\hline & & $\mathrm{G} \rightarrow \mathrm{A}$ & 236 \\
\hline & & $\mathrm{G} \rightarrow \mathrm{T}$ & 258 \\
\hline & & $\mathrm{T} \rightarrow \mathrm{G}$ & 299 \\
\hline & & $\mathrm{A} \rightarrow \mathrm{G}$ & 357 \\
\hline & & $\mathrm{G} \rightarrow \mathrm{C}$ & 387 \\
\hline & & $\mathrm{G} \rightarrow \mathrm{T}$ & 473 \\
\hline
\end{tabular}

Group four included 11 isolates of B. canis. The haematological examination did not reveal the presence of Babesia merozoites in any of the dogs infected with these parasites. Typical clinical symptoms of babesiosis were not observed in the animals either. The differences in the nucleotide substitutions in the representatives of each group are presented in Table 1 .

Results of the epidemiological study. Table 2 presents the occurrence of each protozoa group in the dogs from the provinces examined.

Table 2. The occurrence of each protozoa group in the dogs by province

\begin{tabular}{llllll}
\hline Province & $\begin{array}{l}\text { Group } \\
1\end{array}$ & $\begin{array}{l}\text { Group } \\
2\end{array}$ & $\begin{array}{l}\text { Group } \\
3\end{array}$ & $\begin{array}{l}\text { Group } \\
4\end{array}$ & Total \\
\hline Lublin & 16 & 18 & 15 & 11 & 60 \\
\hline Mazowieckie & 17 & 20 & 23 & - & 60 \\
\hline Podkarpacie & 39 & 21 & - & - & 60 \\
\hline Podlasie & 35 & 25 & - & - & 60 \\
\hline Total & 107 & 84 & 38 & 11 & 240 \\
\hline
\end{tabular}

In the Podlasie and Podkarpacie provinces only cases of acute babesiosis were reported, and protozoa from groups 1 and 2 (EU622792 and EU622793) were isolated only from the sick dogs.

The Lublin and Mazowieckie provinces showed the presence both of strains developing acute babesiosis and strains developing an atypical disease course. The acute strains comprised the first and second groups (EU622792 and EU622793) and in Lublin province, half of the third group. The atypical strains accounted for the other half of the third group in Lublin's case but for the whole third group in regard to Mazowieckie.

The presence of representatives of three groups responsible for the development of acute babesiosis (representatives of groups 1 and 2 and seven isolates of group 3) and the atypical form of the disease (the isolates of group 3), as well as subclinical babesiosis (all isolates of group 4) were observed only in the Lublin province (Table 3). The full spectrum of disease courses was present only in the Lublin province. The strains giving rise to acute babesiosis (the isolates of groups 1 and 2 and half of group 3), strains causing atypical course (half of group 3), and strains inflicting only subclinical babesiosis (group 4) were all present here (Table 3 ). 
Table 3. The association between the clinical course of the disease in dogs, and the strain of protozoa responsible for the development of babesiosis

\begin{tabular}{|c|c|c|c|c|c|}
\hline \multirow[b]{2}{*}{ Group } & \multirow[b]{2}{*}{ Course of the disease } & \multicolumn{4}{|c|}{ Number of isolates } \\
\hline & & Lublin & Mazowieckie & Podlasie & Podkarpacie \\
\hline 1 & Acute & 16 & 17 & 35 & 39 \\
\hline 2 & Acute & 18 & 20 & 25 & 21 \\
\hline 3 & Acute/atypical & $7 / 8$ & $0 / 23$ & $0 / 0$ & $0 / 0$ \\
\hline \multirow[t]{2}{*}{4} & Subclinical & 11 & 0 & 0 & 0 \\
\hline & Total & 60 & 60 & 60 & 60 \\
\hline
\end{tabular}

\section{Discussion}

As demonstrated by the results of many previous studies, canine babesiosis is a disease endemic to Poland $(3,5,20,21)$. This situation is a result of Dermacentor reticulatus ticks becoming more widespread, because these ticks transmit the parasites $(5,21)$. A few years ago the disease was diagnosed only in the eastern part of Poland, and the results of this study show that these regions are indeed areas of endemic babesiosis $(5,9)$.

PCR is very useful in diagnosing babesiosis. Firstly, PCR detection is more sensitive than a direct blood smear examination. Secondly, the detection of DNA of a specific pathogen can be considered as evidence of an active - and therefore ongoing infection. In addition to this, unlike direct detection by light microscopy or serological examinations, PCR allows for a more reliable identification of the causative species infecting the dog. PCR is a useful screening strategy considering that many dogs remain chronically infected with piroplasms. Their chronically infected status predisposes these dogs to relapse or to fail to improve from a chronic clinical state. Under these circumstances, PCR can be used to establish whether the infection remains or not (16).

Until now, only one Babesia species - B. canis had been diagnosed in dogs in Poland (10). Previously, when the 18S rRNA gene was analysed, two genotypes of these protozoa responsible for the development of the acute form of the disease were identified; they are referred to as $18 \mathrm{~S}$ RNA-A and 18S RNA-B $(2,3,8)$. However, recent studies by Łyp et al. (13) revealed the presence of another genotype of the protozoa in Poland, which caused subclinical babesiosis in $10 \mathrm{dogs}$. Patients with this type of infection may serve as a source of Babesia parasite that is important from an epidemiological point of view (11).

As shown by the results of other studies, the frequency of asymptomatic infections in dogs is low. Beck et al. (6) found subclinical babesiosis in only 29 out of $848(3.42 \%)$ dogs not showing clinical symptoms of the disease. The observation of WelcFalęciak et al. (17) conducted in Poland showed that the subclinical form of the disease may be a more significant problem than is generally assumed. Using PCR, they detected the genetic material of B. canis in the blood of 20 out of $79(25.3 \%)$ apparently healthy dogs. These results, although obtained from a not very large group of patients, indicate a significant risk of this type of infection in dogs and the need to develop sensitive diagnostic tests able to confirm subclinical infections.

The results of the present study partly confirm the previous observations by Łyp et al. (13) that the strain of protozoa discovered in 2015 is actually responsible mainly for the development of the atypical form of piroplasmosis; however, in seven dogs the infection resulting from this strain induced the development of a severe form of the disease.

Furthermore, our own studies also revealed the existence of another protozoa genotype responsible for the development of disease with a subclinical course, whose occurrence has so far been limited to the Lublin region. This indicates a continuous genetic evolution of the protozoa and the formation of new strains, where changes in the genome are related to changes in strain virulence (8).

Analysing the sequence of $B$. canis isolates obtained during our study with regard to the geographical area where they were collected, a pattern can be discerned. Although in the whole area of eastern Poland, similar to the whole of Europe $(2,8)$, the presence of EU622792 and EU622793 is observed and the genotypes are responsible for the development of acute babesiosis in dogs. The protozoa isolates responsible for the development of the atypical and subclinical forms of the disease have only been discovered in the Lublin and Mazowieckie provinces, where the number of cases of the disease seems to be the highest in Poland $(5,19)$.

These results indicate the appearance of new B. canis genotypes in Poland. It is still necessary to study the relationship between the genetic structure of protozoa, their geographical distribution, and the course of the disease in dogs (3). This analysis could provide the basis for developing a map of the progress of the disease among dogs in Poland and will also help to identify some factors facilitating the development of the infection.

Conflict of Interests Statement: The authors have no conflict of interests regarding the publication of this article. 
Financial Disclosure Statement: The authors declare that the research and the article were funded from statutory sources.

Animal Rights Statement: The authors declare that the experiments on animals were conducted in accordance with local Ethical Committee laws and regulations as regards the care and use of laboratory animals.

\section{References}

1. Adaszek Ł., Winiarczyk S.: Dogs babesiosis-still actually problem. Wiad Parazytol 2008, 54, 109-115.

2. Adaszek Ł., Winiarczyk S.: Molecular characterization of Babesia canis canis isolates from naturally infected dogs in Poland. Vet Parasitol 2008, 152, 235-241.

3. Adaszek Ł., Winiarczyk S., Skrzypczak M.: The clinical course of babesiosis in 76 dogs infected with protozoa parasites Babesia canis canis. Pol J Vet Sci 2009, 12, 81-87.

4. Adaszek Ł., Winiarczyk S., Górna M.: From piroplasmosis to babesiosis-problems with classification of Babesia protozoa isolated from dogs. Wiad Parazytol 2010, 56, 111-115.

5. Adaszek Ł., Martinez A.C., Winiarczyk S.: The factors affecting the distribution of babesiosis in dogs in Poland. Vet Parasitol 2011, 181, 160-165.

6. Beck R., Vojta L., Mrljak V., Marinculic A., Beck A., Zivicnjak T., Cacció S.M.: Diversity of Babesia and Theileria species in symptomatic and asymptomatic dogs in Croatia. Int J Parasitol 2009, 39, 843-848.

7. Carret C., Walas F., Carcy B., Grande N., Précigout É., Moubri K., Schetters T., Gorenflot A.: Babesia canis canis, Babesia canis vogeli, Babesia canis rossi: differentiation of three subspecies by restriction fragment length polymorphism analysis on amplified small subunit ribosomal RNA genes. J Eukaryot Microbiol 1999, 46, 298-303.

8. Carcy B., Randazzo S., Depoix D., Adaszek Ł., Cardoso L., Baneth G., Gorenflot A., Schetters T.P.:. Classification of Babesia canis strains in Europe based on polymorphism of the Bc28.1-gene from the Babesia canis Bc28 multigene family. Vet Parasitol 2015, 211, 111-123.

9. Dzięgiel B., Kubrak T., Adaszek Ł., Dębiak P., Wyłupek D., Bogucka-Kocka A., Lechowski J., Winiarczyk S.: Prevalence of
Babesia canis, Borrelia burgdorferi sensu lato, and Anaplasma phagocytophilum in hard ticks collected from meadows of Lubelskie Voivodship. Bull Vet Inst Pulawy 2014, 58, 29-33.

10. Hauschild S., Schein E.: The subspecies specificity of Babesia canis. Berl Munch Tierarztl Wochenschr 1996, 109, 216-219.

11. Ionita M., Mitrea I.L., Pfister K., Hamel D., Buzatu C.M., Silaghi C.: Canine babesiosis in Romania due to Babesia canis and Babesia vogeli: a molecular approach. Parasitol Res 2012, $110,1659-1654$.

12. Kostro K., Stojecki K., Grzybek M., Tomczuk K.: Characteristics, immunological events, and diagnostics of Babesia spp. infection, with emphasis on Babesia canis. Bull Vet Inst Pulawy 2015, 59, 495-504.

13. Łyp P., Adaszek Ł., Furmaga B., Winiarczyk S.: Identification of new 18S rRNA strains of Babesia canis isolated from dogs with subclinical babesiosis. Pol J Vet Sci 2015, 18, 573-577.

14. Macintire D.K., Boudreaux M.K., West G.D., Bourne C., Wright J.C., Conrad P.A.: Babesia gibsoni infection among dogs in the southeastern United States. J Am Vet Med Assoc 2002, 220, 325-329.

15. Sikorski L.E., Birkenheuer A.J., Holowaychuk M.K., McClearyWheeler A.L., Davis J.M., Littman M.P.: Babesiosis caused by a large Babesia species in 7 immunocompromised dogs. J Vet Intern Med 2010, 24, 127-131.

16. Solano-Gallego L., Sainz Á., Roura X., Estrada-Peña A., Miró G.: A review of canine babesiosis: the European perspective. Parasit Vectors 2016, 9, 336. doi: 10.1186/s13071016-1596-0.

17. Welc-Falęciak R., Rodo A., Siński E., Bajer A.: Babesia canis and other tick-borne infections in dogs in Central Poland. Vet Parasitol 2009, 166, 191-198.

18. Zahler M., Schein E., Rinder H., Gothe R.: Characteristic genotypes discriminate between Babesia canis isolates of differing vector specificity and pathogenicity in dogs. Parasitol Res 1998, 84, 544-548.

19. Zygner W., Wedrychowicz H.: Occurrence of hard ticks in dogs from Warsaw area. Ann Agric Environ Med 2006, 13, 355-359.

20. Zygner W., Rapacka G., Gójska-Zygner O., Długosz E., Wedrychowicz H.: Biochemical abnormalities observed in serum of dogs infected with large Babesia in Warsaw (Poland). Pol J Vet Sci 2007, 10, 245-253.

21. Zygner W., Jaros S., Wedrychowicz H.: Prevalence of Babesia canis, Borrelia afzelii, and Anaplasma phagocytophilum infection in hard ticks removed from dogs in Warsaw (central Poland). Vet Parasitol 2008, 153, 139-142. 